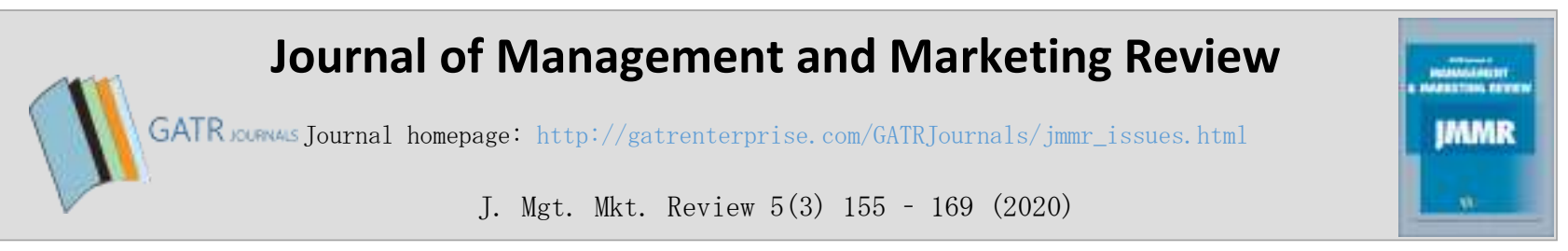

\title{
Factors Influencing Users' Behavioral Intention to Reuse Mobile Financial Services in Bangladesh
}

\author{
Md. Rizvi Khan, ${ }^{1}$ Sirion Chaipoopirutana ${ }^{2}$ \\ ${ }^{1,2}$ Graduate School of Business Assumption University, Bangkok, Thailand
}

\begin{abstract}
Objective - This paper aims to empirically examine the factors influencing the users' behavioral intention to reuse mobile technology to facilitate their financial services in Bangladesh.

Methodology/Technique - A self-administered online survey method was used and 400 responses were collected with Likert-type questions using Google Forms as a medium. A model was developed and proposed based on different technology acceptance models like TAM, UTAUT and similar studies on factors influencing users' intention to adopt and reuse mobile financial services in Bangladesh. The proposed model was tested by performing simple and multiple linear regression using SPSS software.

Findings - The results show that perceived ease of use influences perceived usefulness of mobile financial services but perceived ease of use, perceived usefulness and security have no influence on trust in terms of behavioral intention to reuse mobile financial services in Bangladesh. However, with the exception of trust and perceived financial cost, the remaining variables such as perceived usefulness, perceived ease of use, security, perceived risk, social influence and facilitating conditions significantly influence behavioral intentions to reuse mobile financial services in Bangladesh.

Novelty - This study examines crucial factors spotted in literature in the context of Bangladesh. Earlier papers have primarily focused on traditional banking clients' behavioral intention toward their bank's mobile banking facilities in Bangladesh. This paper is comprehensively designed to identify influential factors of reusing non-traditional mobile financial services like bKash, Rocket, Nagad etc. at the growth level in the industry of Bangladesh. The researcher tried to identify factors influencing both bank and non-bank users to reuse mobile financial services for their digital transactions.
\end{abstract}

Type of Paper: Empirical.

JEL Classification: M31, M39.

Keywords: bKash; Bangladesh; Mobile Banking; Behavioral Intentions; Reuse; Mobile Financial Services.

Reference to this paper should be made as follows: Khan, M.R; Chaipoopirutana, S. (2020). Factors Influencing Users' Behavioral Intention to Reuse Mobile Financial Services in Bangladesh, J. Mgt. Mkt. Review, 5(3) 155 - 169. https://doi.org/10.35609/jmmr.2020.5.3(4)

\section{Introduction}

Going out without cash or cards was a nightmare even few years back when mobile financial services were not convenient, particularly in developing countries. Mobile financial services (MFS) have seen enormous growth in recent years in Bangladesh.

\footnotetext{
* Paper Info: Revised: June 12, 2020

Accepted: September 30, 2020

* Corresponding author: Md. Rizvi Khan

E-mail: rizvi.16.khan@gmail.com

Affiliation: Graduate School of Business Assumption University, Bangkok, Thailand
} 
Mobile financial services refers to the framework for delivering financial transactions that integrates banking with mobile cellular networks, allowing consumers to carry out financial transaction. Azad (2019) reports that Bangladesh's mobile financial services market size is projected to rise at a compound annual growth rate (CAGR) of $30 \%$ compared to $15 \%$ worldwide due to the growth of online shopping, QR code launch and cash back deals by MFS operators. The MFS industry is forecast to rise from over USD100 billion in 2017 to USD 250 billion by 2024 according to US-based Global Business Insights (2019). The number of active users also rose from 2.1 crore in 2017 to 3.73 crore in 2018 . Only 34.76 million active mobile bank accounts were accounted where number of registered clients were 78.6 million (Bangladesh Bank, 2019).

Due to the increasing competitive rivalry amongst mobile financial service providers, each player wants highest number of registered clients to use their services and motivate them with lucrative promotional offers to encourage frequent transactions. bKash currently holds the highest market share in the industry with 58\% immediately followed by Rocket holding $17 \%$ of the market share. mCash and Ucash each hold $8 \%$ of the market share. Cash in and out, money transfers, utility bill payments, shopping and other services are provided by these companies. The number of registered mobile financial service clients is currently around 79.6 million among which only 34.76 million active mobile bank accounts were accounted for (Bangladesh Bank, 2019) which means $57 \%$ are not using mobile financial service accounts actively. These statistic indicate that more than $50 \%$ of users are inactive.

Therefore, studying behavioral intentions to reuse mobile financial service is of great importance. Behavioral intentions to reuse is a significant consideration as it impacts not only user' retention rates but also loyalty towards service providers (Dlodlo, 2015). Users' behavioral intention to reuse is a valuable force to improve a company's sustainable growth as well as long term profitability. Users are attracted to these technologies because of the convenience. However, customers also experience problems such as - ease of use, security, risks, reliability, facilitating condition, credibility, cost, social influence and many more. These variables have been studied in terms of mobile banking by various scholars within the realm of technology acceptance theories. Therefore, it is important to evaluate the factors affecting the behavioral intention to reuse mobile financial services.

Currently, bKash is one of the world's leading providers of mobile financial services. As of now, bKash operates through a network of over 180,000 agents across Bangladesh with more than 30 million registered accounts (bKash, 2019). It is a bank-led, pioneering service provider of mobile financial services in Bangladesh, a subsidiary of BRAC Bank Limited. Therefore, this study focused on bKash and formulated the conceptual framework. Furthermore, the researcher will test and identify the most influential factors effecting behavioral intentions to reuse mobile financial services in Bangladesh.

The findings of this study will provide valuable observations to mobile financial service providers enabling companies and their management to understand behavioral intention to reuse their services by Bangladeshi users. The readers can explore the impact of the determinants to reuse technology based financial services in Bangladesh. Mobile financial service marketers can devise more effective marketing strategies based on the effect of the determinants evidenced in this study that are beneficial for long term customer relationships as well as sustainable growth.

\section{Literature Review}

\subsection{Theories on Technology Acceptance}

The researcher introduced variables such as trust, perceived usefulness, perceived ease of use, security, perceived risk, social influence, perceived financial cost, facilitating conditions and behavioral intention to reuse for the conceptual model of the analysis. These are adopted from the theoretical frameworks of Chawla and Joshi (2019), Makanyeza (2017), Gupta et. al. (2019), Singh and Srivastava (2018) and Sobti (2019). These studies are based on the Theory of Reasoned Action (TRA) (Ajzen \& Fishbein, 1980), the Technology 
Acceptance Model (TAM) (Davis, 1989) and the Unified Theory of Acceptance and Use of Technology (UTAUT) (Venkatesh et. al., 2003). Since human nature has evolved over time, recent findings have become more applicable. The theoretical frameworks chosen to develop the conceptual framework also explore the in-depth history of how Venkatesh et. al. (2003) developed the Unified Theory of Acceptance and the Use of Technology (UTAUT) model by expanding on previous studies. In essence, Venkatesh et al. (2003) had conclusively analyzed and evaluated 8 previous models including the TRA, TAM, TAM2, Theory of Planned Behavior (TPB), Decomposed Theory of Planned Behavior (DTPB), Combined TAM and TPB (C-TAMTPB), Innovation Diffusion Theory (IDT), Motivational Model (MMM), Model of PC Utilization (MPCU) and Social Cognitive Theory ( SCT). Subsequently, they performed a research analysis to further establish the UTAUT concept. Subsequently, Venkatesh et. al. (2012) devised the UTAUT2 based on the UTAUT.

According to Shaikh et. al. (2017), mobile financial services are a banking product or service offered by a bank or a micro-finance entity to conduct monetary and non-monetary transactions using mobile devices and tablets that can follow a bank-led or non-bank-led model.

\subsection{Behavioral Intention to Reuse}

Reusing intention refers to a consumers' behavioral intention to continue to use a product, reduce or increase the consumption of the volume of service from a service provider that was experienced earlier. Behavioral intention to reuse a service means to a criteria of post-adoption behavior where post-adoption indicates a set of behaviors that follow initial acceptance, continuance, routinization, inclusion and adaptation which is usually mentioned in the literature as a synonym for continuance of a service (Rahman et. al., 2017).

\subsection{Perceived Usefulness}

Perceived usefulness is the assumption of a person that using a technology is going to strengthen his/her task quality (Davis, 1989). Alalwan et. al. (2016) proposed that the use of a specific system would grant users higher performance, effectiveness, and productivity for doing a particular job or activity, which was defined as perceived usefulness.

\subsection{Perceived Ease of Use}

Davis (1989) states that perceived ease of use is the degree to which a user believes that using a particular technology is easy. At first, Rogers (1962) asserted perceived ease of use as a determinant of the degree at which a technology is deemed not to be difficult to understand, learn or use.

\subsection{Security}

According to Enck et. al. (2009), security is when someone feels that during transactions, his/her personal information cannot be seen or controlled by any unauthorized party. Mobile banking security is explained as safeguarding user data from fraud or criminal use (Sanayei et. al., 2011).

\subsection{Perceived Risk}

Pavlou (2002) argued that perceived risk stems from the doubt that users experience when they are unable to predict the result of their using decision. Koenig-Lewis et. al. (2010) states that perceived risk is related to the possibility that something is going to happen where the effect of the result is typically undesirable.

\subsection{Trust}

Gefen et. al. (2003) describes trust as a belief that different parties will not behave in an untrustworthy manner and that transaction service providers will provide their service as promised. Trust in mobile financial 
services means the user is comfortable relying on the ability, integrity, and goodwill of the company providing the services (Wang \& Shan, 2013).

\subsection{Social Influence}

Alalwan et. al. (2017) defined social influence as the information and suggestions given by people surrounding a consumer (e.g. friends, relatives, coworkers and superiors) which have an influence on consumer understanding and the desire to accept and use a technology. Customers with a lack of knowledge on technology are influenced by individuals' beliefs or behavior before using mobile financial services (Illia \& Huang, 2015).

\subsection{Perceived Financial Cost}

Perceived financial cost is the extent to which someone thinks it would be more or less costly to use mobile financial service as opposed to other alternatives (Luarn \& Lin, 2005). Mathew et. al. (2014) adds that the cost may include the transactional cost as bank charges, network charges (SMS or data) and mobile device costs.

\subsection{Facilitating Conditions}

Facilitating conditions is the users' consideration that there is sufficient availability of operational and technological infrastructure to use a service (Venkatesh et. al. 2003). Technical infrastructure refers to the system, connectivity, availability, physical instrumental resources and information quality.

\section{Conceptual Framework and Hypothesis}

\subsection{Hypothesis 1}

When users find that using a technology is helpful to them, they are more likely to use that technology more (Premkumar et. al., 2008). Chawla and Joshi (2019), in a neighbor country, India, and other various research from around the world, shows the effect of perceived ease of use on perceived usefulness (Davis, 1989; Gefen et. al., 2003; Luarn \& Lin, 2005; Gu et. al., 2009). Naturally, when a system is easy to use, it is more likely to be useful to the user (Davis, 1993). Therefore, it is posited that:

H10: perceived ease of use has no statistical significant influence of on perceived usefulness.

H1a: perceived ease of use has a statistical significant influence of on perceived usefulness.

\subsection{Hypothesis 2}

Several researchers address the significance of perceived ease of use to enhance the trust of users (Sollner et. al., 2016; Gefen et. al., 2003). Previously mentioned research of Chawla and Joshi (2019) similarly denoted that perceived usefulness does indeed have a favorable impact on trust. The same study carried out confirmed the significance of security as the major indicator of trust (Shin, 2009; Sollner et. al., 2016). In India, empirical studies have validated the above mentioned results (Madan \& Yadav, 2016; Gupta \& Arora, 2017). On this basis, the following hypotheses are developed:

H20: Security, perceived ease of use and perceived usefulness have no influence on trust.

H1a: Security, perceived ease of use and perceived usefulness have an influence on trust.

\subsection{Hypothesis 3}

Perceived usefulness has a positive effect as well as trust has been identified as a significant catalyst for shaping user behavior, usage and intention to use mobile financial services (Hanafizadeh et. al., 2014). 
Previous findings of Madan and Yadav (2016) and Shin (2009) on trust in mobile wallets found corresponding results and (Sollner et. al., 2016) for adopting and repeat using similar technologies. In a study by Juwaheer et. al. (2012) in Mauritius, perceived ease of use was proven to have a positive impact on the acceptance of online banking. Makanyeza (2017) demonstrates that perceived usefulness as well as social influence have a positive impact, while perceived risk had an adverse impact on behavioral intention to accept and continue to use mobile banking services in Zimbabwe.

According to research by Venkatesh et. al. (2012), perceived risk was identified as a crucial driver in the acceptance and continuous use of mobile financial services. Agarwal et. al. (2009) reports that people surrounding the users or their family members had the most social impact on them to use internet banking instead of advertisements. When someone uses a service, he/she convinces others to use the same service as they want to establish their acceptance of the service to be public (Gu et. al., 2009). Koenig-Lewis et. al. (2010) studied perceived cost among young German users to adopt mobile banking and concluded that it is a relevant determinant and a significant predictor of intention to use, which results are consistent with research by Hanafizadeh et. al. (2014), Siddik et. al. (2014) and Ahad et. al. (2012) in Bangladesh. Previously, Chawla and Joshi (2019) as well as Madan and Yadav (2016) showed facilitating conditions have a significant influence on the desire to use mobile financial services. Facilitating conditions (FC) is a significant determinant to predict users' intention toward adapting and using mobile financial services and internet innovations (Hanafizadeh et. al., 2014; Koksal, 2016). From the Indian perspective, Upadhyay and Jahanyan (2016) addressed the significance of facilitating conditions as "structural assurance". Therefore, the researcher constructed the following hypothesis:

H30: Trust, perceived usefulness, perceived ease of use, security, perceived risk, social influence, perceived financial cost, facilitating conditions have no influence on behavioral intention to reuse.

H3a: Trust, perceived usefulness, perceived ease of use, security, perceived risk, social influence, perceived financial cost, facilitating conditions have an influence on behavioral intention to reuse.

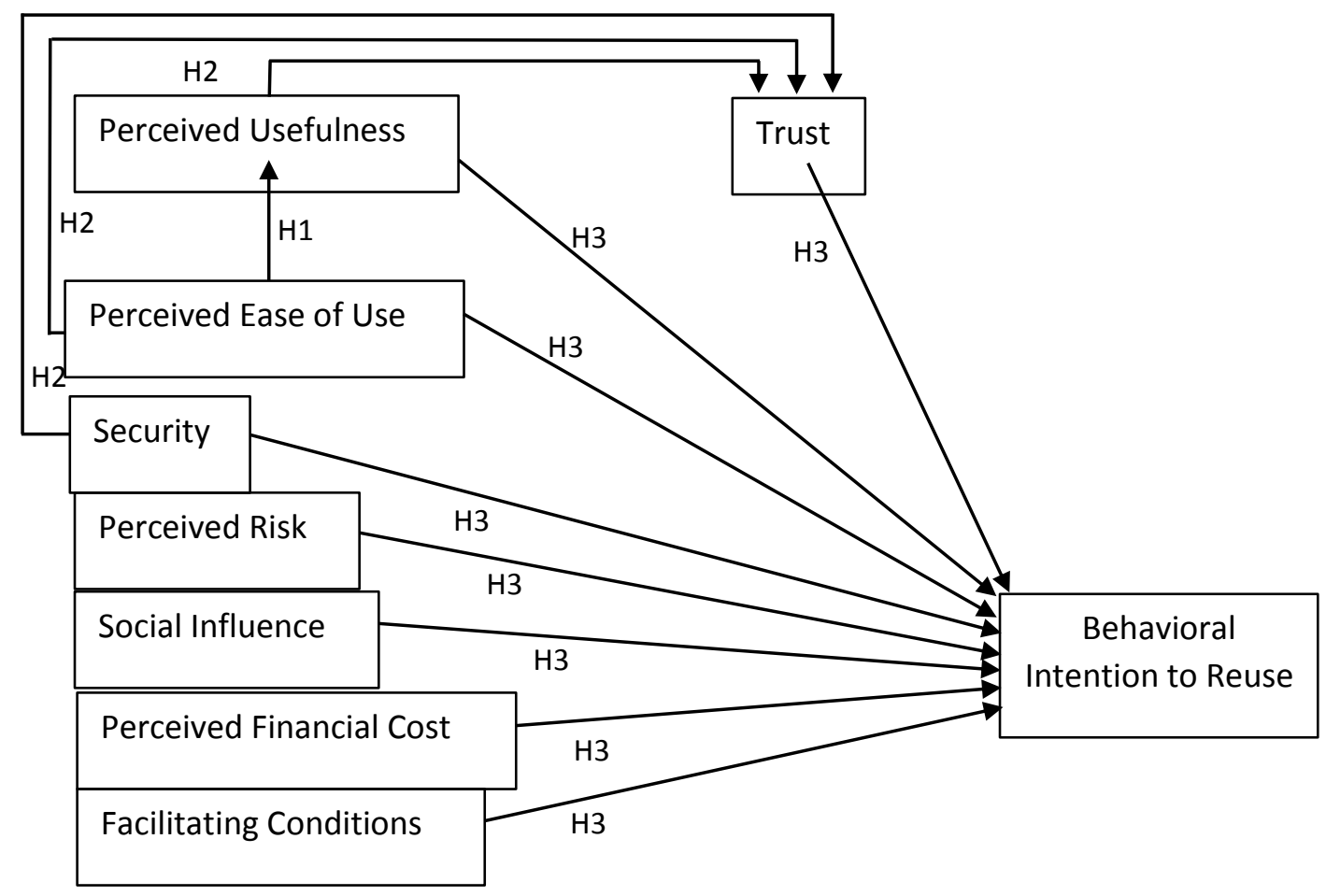

Figure1. Conceptual Framework of "An Empirical Research of Factors Influencing Users Behavioral Intention to Reuse Mobile Financial Services in Bangladesh". 


\section{Research Methodology}

This study uses descriptive research and convenience sampling. A survey research method was used to collect the responses. A 5-point Likert Scale technique with a standardized questionnaire and a selfadministered questionnaire was developed. The survey was translated from English to Bengali so that it was easier for the Bangladeshi respondents to interpret the questionnaire. The researcher selected a market leader, bKash, as the target mobile financial service provider. The target population was Bangladeshi people aged 18 years and older, including male and female respondents who have used bKash services in Bangladesh and who are accessible as the sample to respond the survey questions. The data was gathered from 8 divisions of Bangladesh including Dhaka, Chattogram, Rajshahi, Khulna, Rangpur, Mymensing, Barisal, Sylhet that cover the whole of Bangladesh. The selected locations can represent all the users of bKash in Bangladesh.

\subsection{Sample Size and Procedure}

The researcher chose to use the following statistical equation (Levine et. al., 1999) because the size of the population who have experienced bKash service in Bangladesh is difficult to estimate.

$$
n=\frac{Z^{2} \times p \times(1-p)}{e^{2}}
$$

Where:

$\mathrm{n}=$ sample size.

$\mathrm{Z}=$ Confidence level in standard error units (1.96 for 95\% confidence level),

$e^{2}=.05$, acceptable sampling error.

$p=0.5$, true proportion of the population (Levine et al., 1999).

Hence:

$$
\begin{gathered}
n=\frac{1.96^{2} \times 0.5 \times(1-0.5)}{.05^{2}} \\
=384.16
\end{gathered}
$$

A large enough sample can help to reduce errors (Bartlett et. al., 2001). Therefore 400 respondents were used in order to improve the accuracy of this study. The researcher applied a non-probability sampling method. The study uses convenience sampling to gather input from willingly available respondents. To identify bKash users' behavioral intention to reuse, it was necessary to select the respondents who have experienced bKash mobile financial services, from each of the 8 divisions of Bangladesh. This process matches the data collection procedure. As the responses were collected through online platforms only, such as Facebook, WhatsApp, Imo, Viber, professional platform like LinkedIn and E-mail, any bKash user from any division of Bangladesh can respond to the survey created in google form. The online data collection process covered all the regions of Bangladesh which is valuable, easily accessible, cost effective and efficient. The questionnaire was shaped by the previous studies discussed above.

\subsection{Reliability}

As a pre-test, 100 responses were collected from bKash users of Bangladesh in the third week of January 2020. Questionnaire reliability was analyzed using SPSS software resulting in a Cronbach's alpha result of the variables above 0.6 , which is reliable. A total of 400 responses was collected from the users of bKash services in Bangladesh in which responses from each division must be at least 30 . The questionnaires were 
distributed online for a period of 9 days starting from 26 February 2020. The researcher collected secondary data to build the structure of the research theoretically and systematically based on literature reviews, analysis, results, recommendations, implications and conclusions. The researcher utilized the secondary data to construct the conceptual framework of this study.

\subsection{Statistical Treatments of Data}

Statistical treatments were divided into 2 stages being descriptive analysis and hypothesis testing. The researcher identified 3 hypotheses to represent the influence of the independent variables toward the dependent variable. A simple linear regression was used for H1. For the remaining 2 hypotheses, which are $\mathrm{H} 2$ and $\mathrm{H} 3$, multiple linear regression was used. To examine the individual coefficients as well as the significance of a number of regression coefficients, an F-test was also implemented in this research.

\subsection{Sample Profile and General Information}

The participants consisted of 288 males (72\%) and 112 females (28\%). The highest number of responders were aged between 18-25 (54.5\%) and 26-32 (28.2\%) which represents a younger population. There were $193(48.3 \%)$ students and 119 (29.8\%) job holders, whereas $24(6 \%)$ were self-employed or business owners. Furthermore, 312 (78\%) had earnings of less than 25 thousand BDT (approximately \$300), 68 (17\%) had earnings between 25 to 50 thousand BDT (approximately $\$ 300$ to $\$ 600)$ and the remaining 20 (5\%) had income of 50 thousand BDT (approximately $\$ 600$ ) or more. The number of respondents below graduation level was $240(60 \%)$, whereas $106(26.5 \%)$ were graduates and postgraduates and above as their highest educational level was $54(13.5 \%)$.

A total of $381(95.3 \%)$ of the respondent said that bKash comes first in their mind when they think of mobile banking. In this study, 186 (46.5\%) of the respondents were from the Dhaka division . The other 7 divisions had on average around $30(7.5 \%)$ of the respondents in each division. Further, 264 (66.0 percent) of the respondents used the services less than 6 times a month, whilst $103(25.8 \%)$ used it 6 to 10 times per month and $33(8.3 \%)$ used it more than 10 times a month. Additionally, $366(91.5 \%)$ responded that they will stick to the same brand which is bKash. 196 (49\%) of the respondents mostly use send and receive money services, followed by bills and other payments 90 (22.5\%), cash in and cash out $81(20.3 \%)$ and mobile recharge (top up) 33 (8.3\%) respondents respectively.

Table 1. Summary of General Information Utilizing Frequency and Percentage

\begin{tabular}{|c|c|c|c|c|c|}
\hline Variables & $\begin{array}{c}\text { Frequency } \\
\text { (f) }\end{array}$ & $\begin{array}{c}\text { Percentage } \\
(\%)\end{array}$ & Variables & $\begin{array}{l}\text { Frequency } \\
\text { (f) }\end{array}$ & $\begin{array}{c}\text { Percentage } \\
(\%)\end{array}$ \\
\hline $\begin{array}{l}\text { Gender } \\
\text { Male } \\
\text { Female }\end{array}$ & $\begin{array}{l}288 \\
112\end{array}$ & $\begin{array}{l}72.0 \\
28.0\end{array}$ & $\begin{array}{c}\text { Loyalty } \\
\text { Stick to the same } \\
\text { Love to change } \\
\text { Might consider to change }\end{array}$ & $\begin{array}{c}366 \\
10 \\
24\end{array}$ & $\begin{array}{c}91.5 \\
2.5 \\
6.0\end{array}$ \\
\hline $\begin{array}{c}\text { Age } \\
18 \text { to } 25 \text { years old. } \\
26 \text { to } 32 \text { years old. } \\
33 \text { to } 40 \text { years old. } \\
40 \text { to } 47 \text { years old. } \\
\text { More than } 47 \text { years old. }\end{array}$ & $\begin{array}{c}218 \\
113 \\
56 \\
11 \\
2 \\
\end{array}$ & $\begin{array}{c}54.5 \\
28.2 \\
14.0 \\
2.8 \\
0.5\end{array}$ & $\begin{array}{c}\text { Brand Name in Mind } \\
\text { bKash } \\
\text { Rocket } \\
\text { Nagad } \\
\text { Mcash }\end{array}$ & $\begin{array}{c}381 \\
11 \\
2 \\
6\end{array}$ & $\begin{array}{c}95.3 \\
2.8 \\
0.5 \\
1.5\end{array}$ \\
\hline $\begin{array}{c}\text { Income } \\
\text { Less than 25,000 BDT. } \\
25,000 \text { to 50,000 BDT. } \\
\text { More than 50,000 BDT. }\end{array}$ & $\begin{array}{c}312 \\
68 \\
20 \\
\end{array}$ & $\begin{array}{c}78.0 \\
17.0 \\
5.0 \\
\end{array}$ & $\begin{array}{l}\text { Using Frequency } \\
\text { Less than } 6 \text { times } \\
6 \text { to } 10 \text { times } \\
\text { More than } 10 \text { times }\end{array}$ & $\begin{array}{c}264 \\
103 \\
33 \\
\end{array}$ & $\begin{array}{c}66.0 \\
25.8 \\
8.3 \\
\end{array}$ \\
\hline Education & & & Location & & \\
\hline
\end{tabular}




\begin{tabular}{|c|c|c|c|c|c|}
\hline SSC/O-level or Below & 38 & 9.5 & Dhaka & 186 & 46.5 \\
HSC/A-level & 202 & 50.5 & Chattogram & 32 & 8.0 \\
Bachelor & 106 & 26.5 & Rajshahi & 31 & 7.8 \\
Master & 52 & 13.0 & Khulna & 30 & 7.5 \\
Doctoral & 2 & 0.5 & Mymensing & 31 & 7.8 \\
& & & Sylhet & 30 & 7.5 \\
& & & Rangpur & 30 & 7.5 \\
\hline Occupation & & & Barisal & 196 & 49.0 \\
Student & 193 & 48.3 & Send and receive money & 33 & 8.3 \\
Job Holder & 119 & 29.8 & Mobile recharge (Top up) & 31 & 20.3 \\
Unemployed & 64 & 16.0 & Cash in an cash out & 80 & 22.5 \\
Business Owner & 24 & 6.0 & Bills and other payment & 90 & \\
\hline
\end{tabular}

Relevantly, $100 \%$ of the business owners' responses show that the most commonly used service was send and receive money services. Student with $14.5 \%$ stood highest by choosing top up or mobile recharge service as their most used service. $29.4 \%$ of the job holder responded that they use the services to pay bills (utility) most of the time which is the highest group. Almost $70 \%$ of the respondents among the low income group earning less than 25000 BDT (\$300) use the services less than 6 time in a month. $85 \%$ of the high income respondents earning more than 50000 BDT $(\$ 600)$ responded that they use the services more than 10 times in a month. Hence, increased income contributes to an increase in monthly use of the services.

The results of the reliability test achieved the following results: trust 0.755 , perceived usefulness 0.665 , perceived ease of use 0.698 , security 0.710 , perceived risk 0.785 , social influence 0.691 , perceived financial cost 0.814 , facilitating conditions 0.696 and behavioral intention to reuse 0.737 as Cronbach's alpha value which indicates that the questionnaire is reliable.

Table 2. Mean Value of Questionnaire

\begin{tabular}{|c|c|c|c|}
\hline Variable & Operational Components & $\begin{array}{l}\text { Mean } \\
\text { Value }\end{array}$ & Source \\
\hline $\begin{array}{l}\text { Perceived } \\
\text { Usefulness }\end{array}$ & $\begin{array}{l}\text { Using bKash enables me to do my financial transaction quicker. } \\
\text { Using bKash makes it easier to do my financial transactions. } \\
\text { bKash enhances the efficiency of my financial transactions. } \\
\text { bKash service is useful for financial transaction. }\end{array}$ & $\begin{array}{l}3.21 \\
3.27 \\
3.34 \\
3.45\end{array}$ & $\begin{array}{c}\text { Makanyeza } \\
\text { (2017) }\end{array}$ \\
\hline $\begin{array}{c}\text { Perceived } \\
\text { Ease of Use }\end{array}$ & $\begin{array}{l}\text { bKash financial service is clear and understandable. } \\
\text { Step by step navigation of bKash mobile wallet system is easy to understand. } \\
\text { I like the fact that payments done through bKash require minimum effort. } \\
\text { It is easy to transfer money through bKash as minimum steps are required. } \\
\text { It is easy to become skillful in maintaining bKash account. } \\
\text { bKash is easy to use. }\end{array}$ & $\begin{array}{l}3.38 \\
3.22 \\
3.20 \\
3.25 \\
3.16 \\
3.55\end{array}$ & $\begin{array}{l}\text { Chawla and } \\
\text { Joshi (2019); } \\
\text { Makanyeza } \\
\text { (2017) }\end{array}$ \\
\hline Security & $\begin{array}{c}\text { Technology used in bKash is very secure. } \\
\text { My bKash account information will remain confidential. } \\
\text { My bKash transaction information will not be lost. } \\
\text { I am confident of making transactions through bKash account. } \\
\text { bKash has a potential to be safer than traditional transaction options (such as } \\
\text { credit cards and cash). } \\
\text { The chances of losing money stored in bKash account are low. } \\
\text { Transactions conducted through bKash account are secure. }\end{array}$ & $\begin{array}{l}3.09 \\
3.13 \\
3.06 \\
3.19 \\
2.97 \\
2.95 \\
3.21\end{array}$ & $\begin{array}{l}\text { Chawla and } \\
\text { Joshi (2019) }\end{array}$ \\
\hline Trust & $\begin{array}{l}\text { bKash keeps customers' interests best in mind. } \\
\text { bKash keeps its promises and commitments. } \\
\text { In case of any issue bKash will provide me assistance. }\end{array}$ & $\begin{array}{l}3.70 \\
4.19 \\
4.15\end{array}$ & $\begin{array}{l}\text { Chawla and } \\
\text { Joshi (2019) }\end{array}$ \\
\hline
\end{tabular}




\begin{tabular}{|c|c|c|c|}
\hline & $\begin{array}{l}\text { bKash follows consumer laws. } \\
\text { I trust transactions happening through bKash financial service. }\end{array}$ & $\begin{array}{l}4.23 \\
4.30\end{array}$ & \\
\hline $\begin{array}{l}\text { Perceived } \\
\text { Risk }\end{array}$ & $\begin{array}{l}\text { The likelihood of frauds in using bKash is low. } \\
\text { I do not hesitate to use bKash payment modes for fear of making mistakes I } \\
\text { cannot correct. } \\
\text { I won't fear of providing my confidential information to bKash. } \\
\text { Using bKash transaction is not riskier than traditional transaction methods } \\
\text { (cash and cards). } \\
\text { bKash protect my transaction and privacy information. }\end{array}$ & $\begin{array}{l}4.64 \\
4.21 \\
4.19 \\
4.23 \\
4.22\end{array}$ & Sobti (2019); \\
\hline $\begin{array}{c}\text { Social } \\
\text { Influence }\end{array}$ & $\begin{array}{l}\text { People who are important to me think that I should continue using bKash. } \\
\text { Mass media (e.g. TV, newspaper, articles, and radio) influence me to use } \\
\text { bKash. } \\
\text { I use bKash because the service is widely used by people around me. } \\
\text { I use bKash because it is a current trend. } \\
\text { Friends and family have influence on my decision to continue using bKash. }\end{array}$ & $\begin{array}{l}4.24 \\
4.27 \\
4.15 \\
4.23 \\
4.26\end{array}$ & $\begin{array}{c}\text { Makanyeza } \\
\text { (2017); Sobti } \\
\text { (2019); }\end{array}$ \\
\hline $\begin{array}{c}\text { Perceived } \\
\text { Financial } \\
\text { Cost }\end{array}$ & $\begin{array}{l}\text { There is no hidden charges while using bKash transaction service } \\
\text { bKash transaction service is not expensive due to transaction fees. } \\
\text { To use bKash service, I do not need an expensive handset. } \\
\text { To use bKash service I do not need more internet expense. } \\
\text { I do not spend more when using bKash mobile payment modes. }\end{array}$ & $\begin{array}{l}4.38 \\
3.89 \\
4.40 \\
4.36 \\
4.36\end{array}$ & Sobti (2019); \\
\hline $\begin{array}{l}\text { Facilitating } \\
\text { Conditions }\end{array}$ & $\begin{array}{l}\text { I can easily find a person who can help me out if I get stuck while using } \\
\text { bKash. } \\
\text { My living and working environment supports me to use bKash transaction } \\
\text { service. } \\
\text { Most of the merchants from whom I buy goods/service, accept bKash } \\
\text { transaction. } \\
\text { I have the resources (eg: mobile, connection) necessary to use bKash } \\
\text { services. } \\
\text { I have the knowledge necessary to use bKash. }\end{array}$ & $\begin{array}{l}4.41 \\
4.48 \\
4.33 \\
4.36\end{array}$ & $\begin{array}{l}\text { Chawla and } \\
\text { Joshi (2019); } \\
\text { Sobti (2019) }\end{array}$ \\
\hline $\begin{array}{c}\text { Behavioral } \\
\text { Intention to } \\
\text { Reuse }\end{array}$ & $\begin{array}{l}\text { I have planned to continue to use bKash service more in near future. } \\
\text { I will use bKash when shopping in the malls. } \\
\text { I will use bKash when shopping online. } \\
\text { I will use bKash for my regular monthly payments (bills). } \\
\text { I prefer using bKash than other transaction modes (cash, cards). } \\
\text { I recommend others to use bKash service. }\end{array}$ & $\begin{array}{l}4.42 \\
4.41 \\
4.41 \\
3.92 \\
3.84 \\
4.23\end{array}$ & $\begin{array}{l}\text { Chawla and } \\
\text { Joshi (2019); } \\
\text { Sobti (2019); } \\
\text { Gupta et al. } \\
\text { (2019) }\end{array}$ \\
\hline
\end{tabular}

\subsection{Regression Analysis}

H1 was tested using simple linear regression resulting in a correlation coefficient $(\mathrm{R})$ of 0.229 . This means there is a weak positive relationship between perceived ease of use and perceived usefulness and they move to the same direction. The strength of association or coefficient of determination (R2) is equal to 0.053 , which means that an increase or decrease in perceived ease of use will lead to an increase or decrease in perceived usefulness by 5.3\%. The results of the ANOVA (Analysis of Variance) and Regression Coefficient tests obtained a significance value of 0.000 , which is less than $0.05(0.000<0.05)$. Therefore, perceived ease of use significantly influences perceived usefulness at 0.05 significant level. The Regression Coefficient results show a significance level of 0.000 , which is below $0.05(0.000<0.05)$. As a result, the null hypothesis is rejected. Therefore, the results prove that perceived usefulness is statistically influenced by perceived ease of use at the significance level of 0.05 and the beta of unstandardized coefficient between perceived ease of use and perceived usefulness is equal to 0.244. This result is consistent with research by Mazhar et. al. (2014) in Pakistan and Chawla and Joshi (2019) in India. Luarn and Lin (2005), Gu et. al., (2009), Davis (1993) and many more studies have also achieved similar results. 
In $\mathrm{H} 2$, according to the multiple regression analysis model summary, the value of the correlation coefficient (R) is 0.099 which means that perceived ease of use, perceived usefulness and security all have a very weak positive relationship toward trust. The strength of association (R2) is equal to 0.010 , meaning that an increase or decrease in perceived usefulness, perceived ease of use and security will lead to an increase or decrease in trust by $1 \%$. The results of the ANOVA (Analysis of Variance) of regression show that the value of significant is 0.270 , which is more than $0.05(0.270>0.05)$. This means that the null hypothesis is rejected. Therefore, perceived usefulness, perceived ease of use and security have no significant influence on trust at 0.05 significant level. From the regression coefficient table, the results show that perceived usefulness, perceived ease of use and security do not have a statistically significant influence on trust as the significance level of all of those variables are greater than 0.05 . The significance level of the variables are: perceived usefulness $0.108>0.05$, perceived ease of use $0.980>0.05$ and security $0.571>0.05$. Thus, perceived usefulness, perceived ease of use and security have no significant influence on trust. Additionally, the unstandardized coefficient beta value of perceived usefulness is 0.072 , perceived ease of use is 0.001 and security is 0.029. Skvarciany and Jurevic iene (2018) in their study of "Factors Influencing Individual Customers Trust in Internet Banking: Case of Baltic States" state that the factors necessary for trust in all of the examined countries differs in Lithuania, Latvia, and Estonia in different periods of time which can be the consequence of gaining trust gradually and users feel the institution being trustworthy. Similarly, trust at this stage of bKash may not be influenced by perceived ease of use, perceived usefulness and security.

Finally in H3, according to the multiple regression analysis model summary, the value of the correlation coefficient (R) was 0.674 which means that trust, perceived usefulness, perceived ease of use, security, perceived risk, social influence, perceived financial cost and facilitating conditions all have a strong positive relationship toward behavioral intention to reuse. The strength of association (R2) is equal to 0.454 , which means that an increase or decrease in trust, perceived usefulness, perceived ease of use, security, perceived risk, social influence, perceived financial cost or facilitating conditions will lead to an increase or decrease in trust by $45.4 \%$. The results of the ANOVA (Analysis of Variance) of regression show that the value of significance is 0.000 , which is less than $0.05(0.000<0.05)$ meaning the null hypothesis is rejected.

Therefore, it can be said that at least 1 of the independent variables has an influence on behavioral intention to reuse at a significance level of 0.05. From the regression coefficient in Table 5.33, it can be concluded that perceived usefulness, perceived ease of use, security, perceived risk, social influence, facilitating conditions have a significance level of $0.000<0.05,0.000<0.05,0.000<0.05,0.000<0.05$, $0.001<0.05$ and $0.000<0.05$ respectively. The remaining 2 variables, being trust and perceived financial cost, have a significance level of $0.163>0.05$ and $0.866>0.05$ respectively. Therefore, it can be concluded that perceived usefulness, perceived ease of use, security, perceived risk, social influence and facilitating conditions have a statistical influence on behavioral intention to reuse at a 0.05 significance level whereas trust and perceived financial cost have no statistical influence on behavioral intention to reuse at a 0.05 significance level. Islam (2016) and Islam and Hossain (2015) in Bangladesh and Chawla and Joshi (2019) in India studied mobile payment and mobile banking and conclude that perceived usefulness, perceived ease of use, security and facilitating condition are significant factors influencing behavioral intention to use. In the study of Islam and Hossain (2015) in Bangladesh and of Makanyeza (2017) in Zimbabwe, the results show that perceived risk and social influence impact on users' behavioral intention to use mobile banking services. Previous studies by Koenig-Lewis et. al., (2010) examined young users which is also the major group of the sample size in this study. Further, Koksal (2016) in Lebanon and Mazhar et. al. (2014) in Pakistan show that trust has no significant influence in the adoption and use of mobile banking. Research by Micheni et. al. (2013) on the effect of financial costs on customers' behavioral intention to adopt and use mobile money in Kenya indicates that financial costs do not influence behavioral intention to use mobile financial services.

Additionally, the unstandardized coefficient beta value of perceived usefulness 0.162 indicates that if perceived usefulness increases and the other variables remain constant, behavioral intention to reuse will increase by $16.2 \%$ and vice versa. Similarly, perceived ease of use will increase by 0.139 or $13.9 \%$, security 
by 0.148 or $14.8 \%$, trust by 0.057 or $5.7 \%$, perceived risk by 0.259 or $25.9 \%$, social influence by 0.166 or $16.6 \%$, perceived financial cost by 0.007 or $0.7 \%$ and facilitating conditions by 0.228 or $22.8 \%$ when the other variables remain constant.

Table 3. Summary of Hypothesis Testing Result

\begin{tabular}{|c|c|c|c|c|}
\hline Hypothesis & $\begin{array}{c}\text { Statistical } \\
\text { Analysis }\end{array}$ & $\begin{array}{c}\text { Level of } \\
\text { Significance }\end{array}$ & $\begin{array}{l}\text { Coefficient Beta } \\
\text { (ß) Value }\end{array}$ & Results \\
\hline $\begin{array}{l}\text { H10: There is no statistical significant } \\
\text { influence of perceived ease of use on } \\
\text { perceived usefulness. } \\
\text { Perceived Ease of Use }\end{array}$ & $\begin{array}{c}\text { Simple } \\
\text { Linear } \\
\text { Regression }\end{array}$ & 0.000 & 0.244 & Reject H10 \\
\hline $\begin{array}{c}\text { H20: Security, perceived ease of use and } \\
\text { perceived usefulness have no influence on } \\
\text { trust. } \\
\text { Perceived Usefulness } \\
\text { Perceived Ease of Use } \\
\text { Security }\end{array}$ & $\begin{array}{c}\text { Multiple } \\
\text { Linear } \\
\text { Regression }\end{array}$ & $\begin{array}{l}0.108 \\
0.980 \\
0.571\end{array}$ & $\begin{array}{c}0.072 \\
-0.001 \\
0.029\end{array}$ & $\begin{array}{c}\text { Failed to } \\
\text { Reject H20 }\end{array}$ \\
\hline $\begin{array}{c}\text { H30: Trust, perceived usefulness, perceived } \\
\text { ease of use, security, perceived risk, social } \\
\text { influence, perceived financial cost, facilitating } \\
\text { conditions have no influence on behavioral } \\
\text { intention to reuse. } \\
\text { Trust } \\
\text { Perceived Usefulness } \\
\text { Perceived Ease of Use } \\
\text { Security } \\
\text { Perceived Risk } \\
\text { Social Influence } \\
\text { Perceived Financial Cost } \\
\text { Facilitating Conditions }\end{array}$ & $\begin{array}{c}\text { Multiple } \\
\text { Linear } \\
\text { Regression }\end{array}$ & $\begin{array}{l}0.163 \\
0.000 \\
0.000 \\
0.000 \\
0.000 \\
0.001 \\
0.866 \\
0.000\end{array}$ & $\begin{array}{l}0.162 \\
0.139 \\
0.148 \\
0.057 \\
0.259 \\
0.166 \\
0.007 \\
0.228\end{array}$ & Reject H30 \\
\hline
\end{tabular}

\section{Discussion}

According to the results of this study, perceived usefulness of bKash depends on how easy the service is designed for the users. If this service is easy to understand, learn and operate, users can more readily realize the benefit or usefulness of mobile financial services. Mobile financial services are a self-service system whereas in traditional banking, customers receive assistance. Even though mobile financial service is quicker, if non tech-savvy or less educated people do not find the services easy to use, they might not reuse mobile financial services in the future.

However, in this research, trust was not influenced significantly by any of the 3 variables being perceived ease of use, perceived usefulness and security that contradicts many researchers at the initial stage of launching or adapting the mobile financial services in the respective regions. As bKash was established in the middle of 2011 and has since been running their service successfully with tremendous growth in the last 10 years, they have gained a lot of trust among their users. On the other hand, bKash is a subsidiary of BRAC bank who is one of the most well reputed banks of Bangladesh. Last but not the least BRAC is an international development organization based in Bangladesh which has had a tremendous impact on the development of Bangladesh since 1972. All of these factors may influence users to consider bKash as trustworthy rather than how easy, useful and secure the service is. 
Finally, perceived usefulness, perceived ease of use, security, perceived risk, social influence and facilitating conditions have an influence on behavioral intention to reuse mobile financial services in Bangladesh. However, trust and perceived financial cost have no significant influence on behavioral intention to reuse mobile financial services in Bangladesh. When a service is designed for mass use, it should have an impact on their life in a positive way which is effective, efficient and accelerates their positive standard of living. It also should be as easy as possible to use because of the diversity of knowledge and interest of the users in terms of technology. Therefore, people will accept and use the services repeatedly.

Security has a positive influence on behavioral intention to reuse bKash mobile financial services in Bangladesh. Bangladeshi people are quite sensitive to their money and expenditure. Traditional physical banking system security is more visible and easy assistance is more available than mobile financial service system. As a result, more security assurance may increase the number of new users and existing users who are likely to reuse mobile financial service. Facilitating conditions promotes reuse of mobile financial services which means that it will be appreciated by the users if they get the scope to utilize and resources to initiate and control. Government is supporting the establishment of infrastructure for a digital Bangladesh. bKash is creating ways for consumers to use the services every day where a user get motivated to use bKash. This is consistent with the finding that facilitating conditions have a positive influence on behavioral intention to reuse in Bangladesh. The influence of society in human behavior is evident in Bangladesh. As clients of mobile financial services continue to rise in the social network of people, an individual faces greater societal pressure. Therefore, that person is likely to reuse mobile financial services. In this study, social influence has been proven to influence behavioral intention to reuse bKash mobile financial services in Bangladesh.

In dealing with a well reputed company, there is a lower risk of losing personal information and money. It can be concluded upon above discussion that for the mass people if risk is higher, they will use a particular service less and vice versa. This finding is consistent with the results of this study wherein perceived risk positively influences behavioral intention to reuse mobile financial services. In this study, the instrument of perceived risk was positive in meaning or in favor of the service provider.

As discussed above, the reputation of the company and consistency of maintaining the trust of the users may contribute to customers trusting bKash mobile financial services, but does not significantly influence their behavioral intention to reuse the services after the initial stage in the findings of this study. The respondents of this study have a higher chance of being solvent and well-earned which may mean that perceived financial cost will not likely influence their behavioral intention to reuse bKash mobile financial service in Bangladesh. On the other hand, instead of facing the disadvantages of traditional branch banking, they may feel more comfortable staying connected to bKash without considering the below threshold level cost of using bKash services.

\section{Conclusion}

Mobile financial services providers should focus on making their services user friendly and easy to use and understand. For security purposes, a backup plan of the company as well as a strong policy which is effective in safeguarding the interests of the users as well as the company is also important. To reduce the risk of privacy breaches, a strong protocol should be implemented by the management of mobile financial service providers. Those companies should also create awareness programs to continuously educate their users about the potential for fraud by third parties which will keep users alert and reduce perceived risk. Policy makers should strengthen the rules and regulations against those frauds and increase the penalties applicable for those crimes. Creating awareness of security upgrades and new developments in technology and the services being provided should also be emphasized.

This research was conducted in the context of the bKash business to a consumer segment meaning bKash agent services, which falls under the business to business segment, was not considered in this study. Further research may focus on the business to business segment which includes the agent service of bKash 
mobile financial services. The researcher in this study used 8 independent variables to measure reuse intention whereas other variables such as perceived self-efficacy, lifestyle compatibility, attitude, relative advantage, awareness and knowledge can may be considered for future research. On the other hand, demographic factors on the relationships of the variables may also be useful to apply in future research.

This study focuses only respondents who are available online whereas further study may include customers who are not available on online platforms but still use bKash mobile financial services. The research is conducted in one particular service company (bKash) which belongs to the mobile financial services industry in Bangladesh. Other mobile financial service companies such as Rocket, Ucash, Mcash, Nagad may have different results which may be the basis for future research on this topic. Similarly, future research may examine ride sharing services such as Uber, Pathao ad Obhai or food delivery services such as Foodpanda and Pathao Food.

\section{References}

Agarwal, R., Rastogi, S., \& Mehrotra, A. (2009). Customers' perspectives regarding e-banking in an emerging economy. Journal of Retailing and consumer services, 16(5), 340-351. https://doi.org/10.1016/j.jretconser.2009.03.002

Ahad, M. T., Dyson, L. E., \& Gay, V. (2012). An empirical study of factors influencing the SME's intention to adopt mbanking in rural Bangladesh. Journal of Mobile Technologies, Knowledge and Society, 2012, 1. DOI: $10.5171 / 2012.508433$

Ajzen, I., Fishbein, M., \& Heilbroner, R. L. (1980). Understanding attitudes and predicting social behavior (Vol. 278). Englewood Cliffs, NJ: Prentice-hall. https://barbaramyeaers.github.io/jom6r1pal7vr/00-kira-gerlach/lib11ioyJUvM485-9780139364358-understanding-attitudes-and-predicting-social-be.pdf

Alalwan, A. A., Dwivedi, Y. K., \& Rana, N. P. (2017). Factors influencing adoption of mobile banking by Jordanian bank customers: Extending UTAUT2 with trust. International Journal of Information Management, 37(3), 99-110. https://doi.org/10.1016/j.ijinfomgt.2017.01.002

Alalwan, A. A., Dwivedi, Y. K., \& Williams, M. D. (2016). Customers' intention and adoption of telebanking in Jordan. Information Systems Management, 33(2), 154-178. https://doi.org/10.1080/10580530.2016.1155950

Azad, R. I. (2019, January 31). Bangladesh MFS market to gain momentum in 2019, experts say. Theindependent. http://www.theindependentbd.com/post/185535

Bangladesh Bank. (2019, December). Mobile Financial Services (MFS) comparative summary statement. bb.org.bd. https://www.bb.org.bd/fnansys/paymentsys/mfsdata.php

Kotrlik, J. W. K. J. W., \& Higgins, C. C. H. C. C. (2001). Organizational research: Determining appropriate sample size in survey research appropriate sample size in survey research. Information technology, learning, and performance journal, 19(1), 43. https://www.opalco.com/wp-content/uploads/2014/10/Reading-Sample-Size1.pdf

bKash. (2019). About Us. https://www.bkash.com/about-us

Chawla, D., \& Joshi, H. (2019). Consumer attitude and intention to adopt mobile wallet in India-An empirical study. International Journal of Bank Marketing. https://doi.org/10.1108/IJBM-09-2018-0256

Davis, F. D. (1993). User acceptance of information technology: system characteristics, user perceptions and behavioral impacts. International journal of man-machine studies, 38(3), 475-487.https://doi.org/10.1006/imms.1993.1022

Davis, F. D., Bagozzi, R. P., \& Warshaw, P. R. (1989). User acceptance of computer technology: a comparison of two theoretical models. Management science, 35(8), 982-1003. https://doi.org/10.1287/mnsc.35.8.982

Dlodlo, N. (2015). The use of M-payment services in South Africa: a value based perceptions approach. International Business \& Economics Research Journal (IBER), 14(1), 159-178. https://doi.org/10.19030/iber.v14i1.9038

Enck, W., Ongtang, M., \& McDaniel, P. (2009, November). On lightweight mobile phone application certification. In Proceedings of the 16th ACM conference on Computer and communications security (pp. 235245).https://doi.org/10.1145/1653662.1653691

Gefen, D., Karahanna, E., \& Straub, D. W. (2003). Trust and TAM in online shopping: An integrated model. MIS quarterly, 27(1), 51-90.https://doi.org/10.2307/30036519

Global Market Insights (2019, January 28). CISION. PR Newswire. https://www.prnewswire.com/newsreleases/mobile-wallet-market-to-surpass-250bn-by-2024-global-market-insights-inc--891182907.html 
Gu, J. C., Lee, S. C., \& Suh, Y. H. (2009). Determinants of behavioral intention to mobile banking. Expert Systems with Applications, 36(9), 11605-11616. https://doi.org/10.1016/j.eswa.2009.03.024

Gupta, A., \& Arora, N. (2017). Consumer adoption of m-banking: a behavioral reasoning theory perspective. International Journal of Bank Marketing. https://doi.org/10.1108/IJBM-11-2016-0162

Gupta, K. P., Manrai, R., \& Goel, U. (2019). Factors influencing adoption of payments banks by Indian customers: extending UTAUT with perceived credibility. Journal of Asia Business Studies. https://doi.org/10.1108/JABS-07-20170111

Hanafizadeh, P., Behboudi, M., Koshksaray, A. A., \& Tabar, M. J. S. (2014). Mobile-banking adoption by Iranian bank clients. Telematics and Informatics, 31(1), 62-78. https://doi.org/10.1016/j.tele.2012.11.001

Illia, A., Ngniatedema, T., \& Huang, Z. (2015). A conceptual model for mobile banking adoption. Journal of Management Information and Decision Sciences, 18(1), 111. https://search.proquest.com/docview/1718902890?pqorigsite $=$ gscholar $\&$ fromopenview $=$ true

Islam, M. M. (2016). An Investigation of Drivers and Barriers Stimulating in the Acceptance of Mobile Payment in Bangladesh. DOI: 10.13189/ujibm.2016.040402

Islam, M. M., \& Hossain, M. E. (2015). An Investigation of Consumers' Acceptance of Mobile Banking in Bangladesh. International Journal of Innovation in the Digital Economy (IJIDE), 6(3), 16-32. https://doi.org/10.4018/ijide.2015070102

Jackson, B. B., \& Bund, B. (1985). Winning and keeping industrial customers: The dynamics of customer relationships. Free Press.

Juwaheer, T. D., Pudaruth, S., \& Ramdin, P. (2012). Factors influencing the adoption of internet banking: a case study of commercial banks in Mauritius. World Journal of Science, Technology and Sustainable Development. https://doi.org/10.1108/20425941211250552

Karjaluoto, H., Koenig-Lewis, N., Palmer, A., \& Moll, A. (2010). Predicting young consumers' take up of mobile banking services. International journal of bank marketing. https://doi.org/10.1108/02652321011064917

Berenson, M. L., Levine, D. M., Szabat, K. A., \& Stephan, D. (2019). Statistics for Managers Using Microsoft Excel. Pearson. https://www.pearson.com/us/higher-education/program/Levine-Statistics-for-Managers-Using-MicrosoftExcel-2nd-Edition/PGM313817.html

Luarn, P., \& Lin, H. H. (2005). Toward an understanding of the behavioral intention to use mobile banking. Computers in human behavior, 21(6), 873-891. https://doi.org/10.1016/j.chb.2004.03.003

Madan, K., \& Yadav, R. (2016). Behavioural intention to adopt mobile wallet: a developing country perspective. Journal of Indian Business Research. https://doi.org/10.1108/JIBR-10-2015-0112

Makanyeza, C. (2017). Determinants of consumers' intention to adopt mobile banking services in Zimbabwe. International Journal of Bank Marketing. https://doi.org/10.1108/IJBM-07-2016-0099

Mathew, M., Sulphey, M. M., \& Prabhakaran, J. (2014). Perceptions and intentions of customers towards mobile banking adoption. Journal of Contemporary Management Research, 8(1), 83. https://search.proquest.com/docview/1718120940/fulltextPDF/6BC346585E3647FFPQ/1 ?accountid=8401

Mazhar, F., Rizwan, M., Fiaz, U., Ishrat, S., Razzaq, M. S., \& Khan, T. N. (2014). An investigation of factors affecting usage and adoption of internet \& mobile banking in Pakistan. International Journal of Accounting and Financial Reporting, 4(2), 478. https://doi.org/10.5296/ijafr.v4i2.6586

Micheni, E. M., Lule, I., \& Muketha, G. M. (2013). Transaction costs and facilitating conditions as indicators of the adoption of mobile money services in Kenya.https://pdfs.semanticscholar.org/586a/f8bdf62302fe04ded8ff74606fcb2ed8ca93.pdf

Pavlou, P. A., \& Fygenson, M. (2006). Understanding and predicting electronic commerce adoption: An extension of the theory of planned behavior. MIS quarterly, 115-143. https://doi.org/10.2307/25148720

Premkumar, G., Ramamurthy, K., \& Liu, H. N. (2008). Internet messaging: An examination of the impact of attitudinal, normative, and control belief systems. Information \& Management, 45(7), 451-457. https://doi.org/10.1016/j.im.2008.06.008

Rahman, M. N. A., Zamri, S. N. A. S., \& Eu, L. K. (2017). A meta-analysis study of satisfaction and continuance intention to use educational technology. International Journal of Academic Research in Business and Social Sciences, 7(4), 1059-1072.https://doi.org/10.6007/IJARBSS/v7-i4/2915

Rogers, E. M. (1962). The Diffusion of Innovations 1st eds.

Sanayei, A., Ranjbarian, B., Shaemi, A., \& Ansari, A. (2011). Determinants of customer loyalty using mobile payment services in Iran. Interdisciplinary Journal of Contemporary Research in Business, 3(6), 22-34. 
https://www.researchgate.net/publication/216324092_The_Effect_of_ICT_on_Work_Experiences_Iranian_multination al_electrical_manufacturing_companies\#page=22

Shaikh, A. A., Hanafizadeh, P., \& Karjaluoto, H. (2017). Mobile banking and payment system: A conceptual standpoint. International Journal of E-Business Research (IJEBR), 13(2), $14-27$. https://doi.org/10.4018/IJEBR.2017040102

Shin, D. H. (2009). Towards an understanding of the consumer acceptance of mobile wallet. Computers in Human Behavior, 25(6), 1343-1354. https://doi.org/10.1016/j.chb.2009.06.001

Siddik, M. N. A., Sun, G., Yanjuan, C. U. I., \& Kabiraj, S. (2014). Financial inclusion through mobile banking: a case of Bangladesh. Journal of Applied finance and Banking, 4(6), 109. http://www.scienpress.com/Upload/JAFB/Vol\%204_6_7.pdf

Singh, S., \& Srivastava, R. K. (2018). Predicting the intention to use mobile banking in India. International Journal of Bank Marketing.https://doi.org/10.1108/IJBM-12-2016-0186

Skvarciany, V., \& Jurevičienė, D. (2018). Factors influencing individual customers trust in internet banking: Case of Baltic states. Sustainability, 10(12), 4809. https://doi.org/10.3390/su10124809

Sobti, N. (2019). Impact of demonetization on diffusion of mobile payment service in India. Journal of Advances in Management Research.https://doi.org/10.1108/JAMR-09-2018-0086

Söllner, M., Hoffmann, A., \& Leimeister, J. M. (2016). Why different trust relationships matter for information systems users. European Journal of Information Systems, 25(3), 274-287.https://doi.org/10.1057/ejis.2015.17

Upadhyay, P., \& Jahanyan, S. (2016). Analyzing user perspective on the factors affecting use intention of mobile based transfer payment. Internet Research. https://doi.org/10.1108/IntR-05-2014-0143

Venkatesh, V., Morris, M. G., Davis, G. B., \& Davis, F. D. (2003). User acceptance of information technology: Toward a unified view. MIS quarterly, 425-478. https://doi.org/10.2307/30036540

Venkatesh, V., Thong, J. Y., \& Xu, X. (2012). Consumer acceptance and use of information technology: extending the unified theory of acceptance and use of technology. MIS quarterly, 157-178.https://doi.org/10.2307/41410412

Wang, B., \& Shan, C. (2013). The effect of online-to-mobile trust transfer on the foundation of mobile banking trust. Communications and Network, 5(1), 112-115. http://dx.doi.org/10.4236/cn.2013.51B025 